\title{
Plants Arrangement Design in Winter City Based on the Traditional Chinese Garden
}

\author{
Jingwan $\mathrm{Fu}^{1, \mathrm{a}^{*}}$, Ming $\mathrm{Lu}^{1, \mathrm{~b}}$ \\ ${ }^{1}$ School of Architecture, Harbin Institute of Technology, China \\ afu_jw@yahoo.com, bhitlm@126.com,
}

Keywords: Plants arrangement, Landscape design, Traditional Chinese garden, Winter City

Abstract. Plant is an important part of urban landscape features. Although the greening condition of the Winter City is limited, a good plant arrangement design can help to create a more comfortable and beautiful public space, which reflects urban characteristics and promotes ecological development. This paper analyzes the main characteristics of plant arrangement of the traditional Chinese gardens. Based on traditional planting method and the climatic conditions of the cold area, the main points of plants arrangement are summarized from the local plants, the spatial level, the microclimate, color and form, in order to provide design reference on plants arrangement for Winter City.

\section{Introduction}

Winter City is a relatively general concept defined by the winter climate characteristics of the city. It is a city that has a negative impact on the city life due to the long and harsh winter weather [1].

Plant is an important element in landscape. "To get the source from the nature but higher than the nature" is considered as the design essence in the traditional garden, which reflects the philosophy view of the ancient Chinese. In addition to the visual beauty, color coordination, flowering time, the meanings of different plants are also of great importance to reflect the character of the gardener and to bring more spiritual enjoyment.

Plants arrangement design method in Winter City can be learned from Chinese classical gardens, while combined with the modern landscape design principles and the needs of urban public space to create a better landscape art effect, to meet the aesthetic demand, to promote ecological development, and to increase the attractiveness of the cold city at the same time.

\section{Plants arrangement in Chinese classical gardens}

Imitating nature as a principle. Three or five lush trees are often planted in a group and arranged naturally (Fig.1). Trees with dense shade and twisted branches are preferred. The natural landscape is reflected by a few plants which is similar to "a fist as a mountain, a spoon as a river" [2].

Containing abundant cultural connotation. Plants were given different characters, such as lotus represents pure, plum blossom represents noble, pine and cypress represents tenacity and bamboo represents integrity. Moreover, the combination of various plants is special in order to show good luck. For example, cherry-apple tree and peony planted together means full of wealth. Other planting model such as willows are along the river, plums are around the house etc. which are practice experiences ancient Chinese.

Integrating the visual, auditory, olfactory and other sensory experience. Creating different landscape conception through the conversion of day and night, characteristics of the four seasons, weather change and other natural phenomena. In the Humble

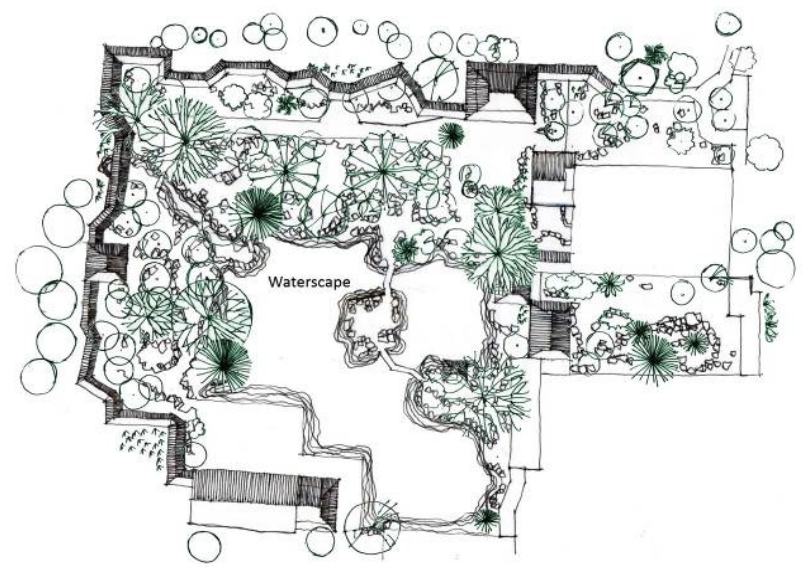

Fig. 1 Plants arrangement in the Lingering Garden 
Administrator's garden, there is a pond with lotus by the window, around the pond are bamboos and Musa basjoo trees. When it rains, the beautiful sound of the rain drops on leaves can be heard inside the house, creating an enjoyable feeling.

Combined with other landscape elements to create an organic integration. Plants are served as an ornament of the stone to highlight its shape and space levels. Pine, bamboo, plum wisteria etc. are often used in this way. Plants can also soften water features, such as wet weeping willow, metasequoia, pterocarya stenoptera, begonia, winter jasmine, forsythia and hibiscus [3]. In addition, plants can also cover the unwanted sight of the construction. Or combined with doors, windows and pergola as an enframed scenery element.

\section{The application of local plants in Winter City}

Using native and suitable plants according to the local conditions of Winter City can not only increase the survival rate, but also reduce the maintenance costs, meanwhile to provide a sustainable environment to attract local birds, insects etc.

Climate in Winter City is often dry, lack of rain, windy and dusty, and the cold season lasts for three to four months a year, so plants with a strong adaptability such as coniferous and deciduous will be the best choice.

Using perennial herbaceous flowers and local wild flowers to create the flower border. It is suitable to do temporary furnishings with the seasonal flowers as their flowering period is short, but the cost is high. If the long-term operation and maintenance costs are taken into account, the native flowers are more economic with appreciation value which have stronger resistance to adapt to the harsh environment.

\section{Arrange the plants with multi-level}

In addition to combine solitary wood with a background wall or with stones to create a static picture applying Zen Aesthetics, using the five-level landscaping method which is recommended in today's real estate landscape to create a rich visual dimension will be another application. Arranging from low to high, the first layer is covered with lawn and ground cover plants as a substrate. The second layer concludes flowers, small shrubs, etc. which can be enjoyed nearby. The third layer are shrubs two to three meters high. The fourth layer consists of small arbors and large shrubs to raise the sense of space. And the fifth layer use tall arbors and evergreen trees as the background and skyline (Fig.2).

The design should pay attention to the plants' color, shape, smell, flowering period and other collocation while arranging them according to the height. With the arrangement of lower plants in front followed by a gradually increased heights, there will be a clear gradient greening and different plants can be fully appreciated. If the configuration is multidimensional from all angles, the environment will not only receive a favorable effect, but also provide a good ventilation. A

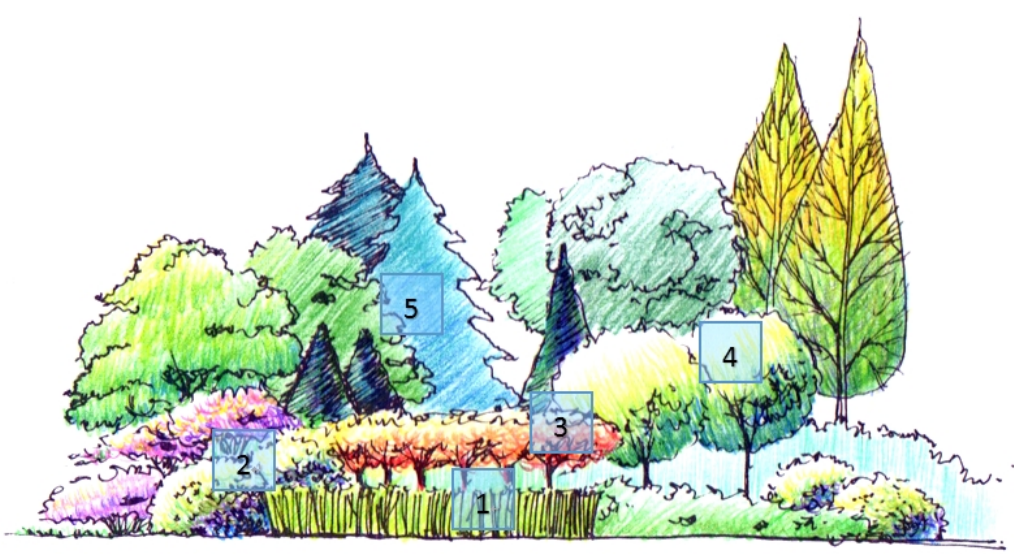

Fig. 2 Concept design of the multi-level plants arrangement 
combination of two to three layers is recommended to apply in the limited conditions (Fig.3).

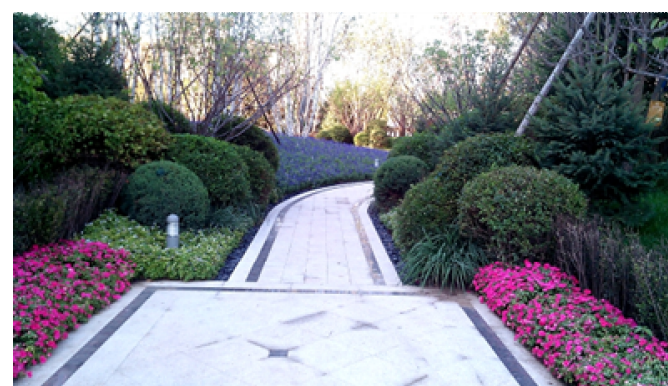

Fig. 3 The multi-level plants arrangement for the pathway

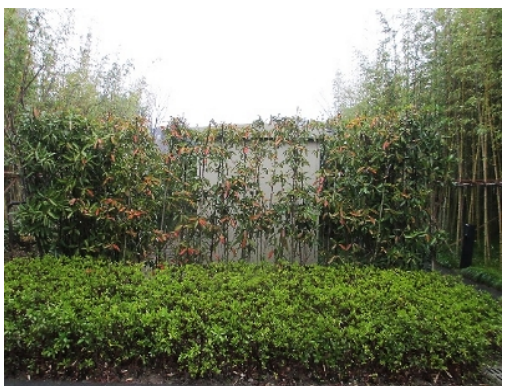

Fig. 4 Plants arrangement to shield the unfavorable landscape

\section{Color design of the plants arrangement}

Plants in different seasons will show a variety of texture effects, color, fragrance etc. The plants arrangement considering the seasonal changes can provide citizens with sensory experience varies by time. For example, Swida alba Opiz has white flowers in spring, green leaves in summer, white fruits in autumn, red branches in winter after the leaves fall to light up the snow. Malus baccata (L.) Borkh has red fruits which do not fall during winter presenting a strong visual effect.

The green quantity can be increased by the use of evergreen plants during the whole year in Winter City. Evergreen trees are usually designed as the background color, deciduous trees are used as the mid-shot, small deciduous trees and evergreen shrubs are used at the front space. Evergreen species provide green space in winter, while the choice of some arbors with warm yellow color leaves which do not fall during winter could improve the dull coloring of the Winter City.

\section{Microclimate design of the plants arrangement}

Plants in landscape should first ensure the ventilation and lighting of the construction. Moreover, the outdoor scene can be seen from the interior is a better design. The north side of the building should choose cold resistant trees or shrubs, the east and west should select the evergreen and deciduous plants should have strong resistance to against cold and the chilly wind. The application of climbing plants of the vertical greening on the building facade creates a natural ecological green wall. Using different heights of the plants can also cover the unfavorable scene while acquire the effect of ecological beauty (Fig.4).

Plants face the windward could block the wind, including conifers and other evergreen coniferous plants which are commonly used to resist cold wind in urban landscape. While planting deciduous trees can also reduce the wind speed. In addition, the leisure space should ensure a certain sunlit hour to encourage people staying outdoor. In winter, the sun is seldom affected by deciduous plants, and some plants' stems shape are beautiful after the leaves fall (Fig.5). In short, combination of evergreen and deciduous plants, trees and shrubs could resist cold in winter and

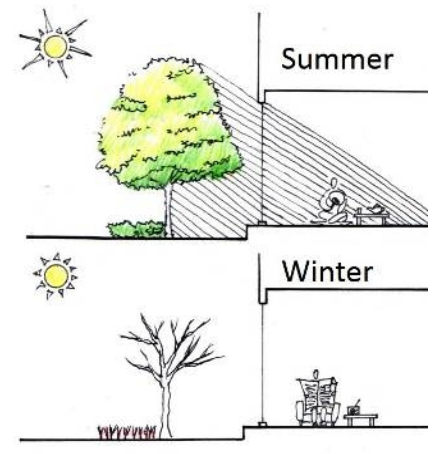

Fig. 5 Different landscape effect of deciduous plant

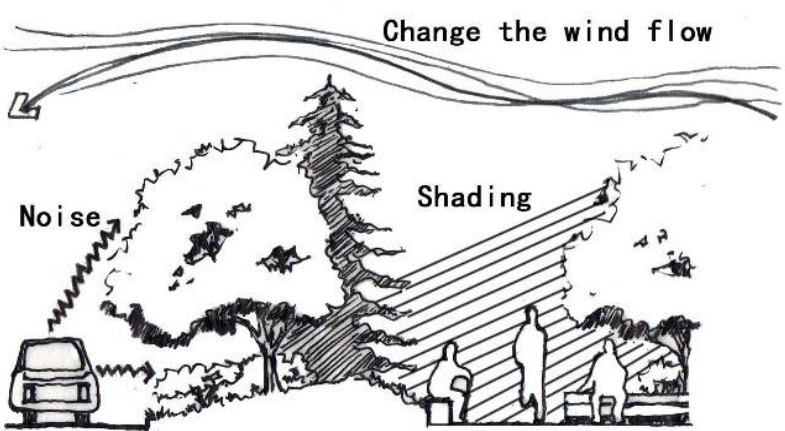

Fig. 6 Microclimate improved by the design of the plants arrangement 
provide shades in summer, thus to improve the living environment comfort (Fig.6).

Some empirical data are used in the Winter City. The ratio of deciduous trees and evergreen trees is 3:1-2:1, the ratio of deciduous shrubs and evergreen shrubs is 3:1-2:1, the ratio of trees (including shrubs) and grass cover is 7:3.

\section{Plants arrangement learning from nature}

Although the modern landscape design does not require planting replication of classical gardens, the basic principles can be the guidance for the new Chinese-style design. Such as 'Plum blossom is beautiful when the branches are twisted, the straight ones lost their charm. The sparse orchid planted in a quiet place are beautiful, the dense ones are out of natural taste. Several plants should be designed into different groups with threes or fives together combined dense and sparse, high and low etc.' At the same time pay attention to the ornamental value of the plant's stem, branch, leaf, flower and fruit, as well as the integration of the changing characteristic with time, space and seasons are essential in the design.

A better way of the plants arrangement is to take use of the plant itself by discovering the natural form using less trimming like the ball type shrubs. And the overall effect is advocated to be simple but with details. In this way the artificial maintenance costs can be reduced, and the Chinese traditional garden "learn from the nature" philosophy can also be reflected. Flower border design should be based on the natural form, a harmonious combination of colors will create a natural landscape effect while the artificial pattern is not recommended. If there is a channel, a pond or other waterscape, planting aquatic plants can achieve aesthetic value and the ecological benefits.

\section{Summary}

Plants arrangement in traditional Chinese garden can still be applied in today's design. The multi-level arrangement based on the feature of terrain, the multi-angle analysis, time and space which also conveys the artful concept 'the scene changes every step you move' from classical gardens, making the landscape interesting. Many other design elements are also of great importance, such as the rational proportion of arbors, shrubs, grass and flowers, as well as their color, shape, florescence, distribution density, the fluctuating canopy line and the organic combination of soft and hard landscape. At the same time, integrating the good meaning of the plant into the design can highlight the theme of different space. It is not necessary to be bound by the traditional configuration practices nor the common combination pattern, the modern Chinese style landscape can be designed in a simple and ecological way creating a comfortable environment in Winter City.

\section{Acknowledgements}

The study was financed by National Natural Science Foundation of China for the major project "Adjustment principle and design method of city microclimate for the severe cold areas" (No. 51438005).

\section{References}

[1] LENG Hong, GUO Enzhang, YUAN Qing, The study on the climate sensitive urban design, J. City Planning Review. 2003(09)50.

[2] Yigang Peng. Chinese Classical Garden Analysis, China Architecture \& Building Press, 2005. (In Chinese)

[3] Chengyuan Guo. Landscape Application of Native Plants in Northern China, China Architecture \& Building Press, 2009. (In Chinese) 